\title{
PKM2 is not required for colon cancer initiated by APC loss
}

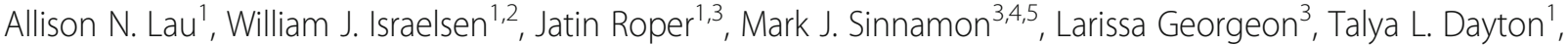 \\ Alissandra L. Hillis ${ }^{1}$, Omer H. Yilmaz ${ }^{1,6}$, Dolores Di Vizio ${ }^{7}$, Kenneth E. Hung ${ }^{3 *}$ and Matthew G. Vander Heiden ${ }^{1,8^{*}}$
}

\begin{abstract}
Background: Cancer cells express the M2 isoform of the glycolytic enzyme pyruvate kinase (PKM2). PKM2 expression is not required for some cancers, and PKM2 loss can promote cancer progression; however, PKM2 has been reported to be essential in other tumor contexts, including a proposed non-metabolic role in $\beta$-catenin nuclear translocation. PKM2 is expressed in colon cancers where loss of the Apc tumor suppressor results in $\beta$-catenin nuclear translocation and aberrant activation of the canonical Wnt signaling pathway. Whether PKM2 is required in this colon cancer context has not been investigated.

Results: Colon tumorigenesis was induced in mice harboring conditional Apc and Pkm2 alleles, and tumor progression was monitored by serial colonoscopy. PKM2 deletion had no effect on overall survival, the number of mice that developed tumors, or the number of tumors that developed per animal. Immunohistochemical analysis demonstrated PKM2 expression in wild-type tumors and the expected loss of PKM2 expression in tumors from Pkm2 conditional mice. Loss of PKM2 resulted in pyruvate kinase M1 expression but had no effect on nuclear $\beta$-catenin staining. These findings are consistent with tumor growth and activated Wnt signaling despite PKM2 loss in this model. We also found a large fraction of human colon cancers had very low or undetectable levels of PKM2 expression.
\end{abstract}

Conclusions: PKM2 is not required for Apc-deficient colon cancer or for nuclear translocation of $\beta$-catenin in Apc-null tumor cells. These findings suggest that PKM2 expression is not required for colon tumor formation or progression.

Keywords: PKM2, APC, $\beta$-catenin, Colon cancer

\section{Background}

Pyruvate kinase is an enzyme that catalyzes the last reaction of glycolysis to produce pyruvate and ATP from phosphoenolpyruvate and ADP. The enzymatic activity of the M2 isoform of pyruvate kinase (PKM2) is regulated by growth signaling and multiple allosteric effectors, coupling PKM2 activity to the metabolic and signaling state of the cell in order to promote proliferative metabolism in appropriate contexts [1,2]. PKM2 is expressed in a wide variety of cancer types and both metabolic and non-metabolic functions for PKM2 in cancer have been suggested [3]; however, the requirement

\footnotetext{
* Correspondence: Kenneth.Hung@pfizer.com; mvh@mit.edu

${ }^{3}$ Department of Medicine, Tufts Medical Center, Boston, MA 02111, USA

${ }^{1}$ Koch Institute for Integrative Cancer Research and the Department of

Biology at Massachusetts Institute of Technology, Cambridge, MA 02139, USA

Full list of author information is available at the end of the article
}

for PKM2 in different cancer contexts remains controversial [4]. For instance, PKM2 has been reported to play a role in driving cancer cell proliferation via signaling functions that are distinct from a role in glycolysis [5-7], including a nuclear function to activate $\beta$-catenin downstream of growth signaling [8]. However, other work has shown that PKM2 is dispensable for the growth and maintenance of xenograft tumors [9], that loss of PKM2 can promote progression of BRCA1 loss-driven breast cancer [10] and medulloblastoma tumor growth [11], and that PKM2 is not required for leukemia or liver tumor formation $[12,13]$.

PKM2 is expressed in colon cancers [14] and has been reported to facilitate colon cancer cell proliferation, migration, and the epithelial-mesenchymal transition [15-17]. Immunohistochemical analysis of human colon tumors revealed that tumors express higher levels of PKM2 as 
compared to paired normal colon tissue and that increased PKM2 expression is associated with greater tumor stage and with lymph node metastasis [15]. Due to the controversy surrounding the requirement for PKM2 by tumors and the functions of this enzyme in cancer, we tested the importance of PKM2 in colon cancer by crossing mice harboring a conditional $P k m 2$ allele [10] to mice with conditional alleles of the $A p c\left(A p c^{C K O}\right)$ tumor suppressor gene [18]. This genetically engineered mouse model of colon cancer has been applied to study the role of oncogenic Kras and Braf in tumorigenesis [19-22]. By comparing mice with and without $P k m 2$ conditional alleles in this model, we sought to determine whether PKM2 is essential for colon cancer initiation and progression following Apc loss.

\section{Results}

PKM2 is expressed in many normal tissues, including the intestine [23], while the pyruvate kinase M1 (PKM1) isoform, encoded by an alternative splice product of the PKM gene, is also expressed in the intestine [14]. To determine which cell types of the colon express each isoform, we performed immunohistochemistry on normal mouse colon tissue using PKM2 and PKM1 isoformspecific antibodies [10]. PKM2 staining was observed in the epithelial cells of the crypts, including crypt base cells that include colon stem cells, but was not prominent in the lamina propria (Fig. 1a). The muscularis propria layer expressed PKM1 but not PKM2 (Fig. 1a). This makes it likely that tumors in this model arise from PKM2-expressing cells.

To generate Apc-deficient colon tumors, colon tissue from $A p c{ }^{C K O}$ mice with and without homozygous conditional $P k m 2$ alleles was exposed to adenoviral $\mathrm{Cre}$, and tumor growth, latency, and multiplicity per animal were determined. In this method, a section of distal colon is transiently ligated and adenovirus-encoding Cre recombinase is introduced into the lumen of the colon. Cre expression in infected cells results in Apc loss and stochastic tumor initiation in the distal colon that can be monitored with optical colonoscopy [18]. Representative colonoscopy images showing colon tumors at various stages of progression are shown in Fig. $1 \mathrm{~b}$.

To verify that $P k m 2$ was deleted in tumors from $A p c^{f l o x / f l o x} ; P k m 2^{f l o x / f l o x}$ mice, we analyzed genomic DNA from $A p c^{\text {flox flox }} ; P \mathrm{~km} 2^{+/+}$and $A p c^{\text {flox/flox }} ; P \mathrm{~km} 2-$ flox/flox colon tumors to confirm that PKM2 recombination had occurred (Fig. 2a). There was no significant difference in the fraction of mice developing one or more tumors 3 weeks, 6 weeks, or at later time points following Cre administration in

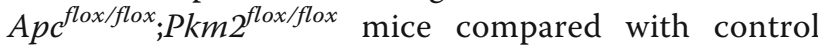
$A p c^{\text {flox/flox }} ; P k m 2^{+/+}$mice (Fig. 2b). There were also no differences in the number of tumors arising per mouse (Fig. 2c) over the same period of time. Overall survival was not significantly different between $A p c^{\text {flox/flox }} ; P k m 2^{+/+}$and $A p c^{\text {flox/flox }} ; P k m 2^{\text {flox } / \text { flox }}$ mice with Apc loss driven colon tumors (Fig. 2d).

We also analyzed pyruvate kinase expression in tumors isolated from these mice using immunohistochemistry with pyruvate kinase isoform-specific antibodies. As expected, analysis of colon lesions showed that PKM2 wild-type tumors expressed almost exclusively PKM2 (Fig. 3a). Similar to breast tumors [10], some of these PKM2 wild-type tumor cells appeared to express very little PKM2 despite a lack of PKM1 expression (Fig. 3a, Additional file 1: Figure S1A). PKM2 expression in normal colon tissue and PKM1 expression in the lamina

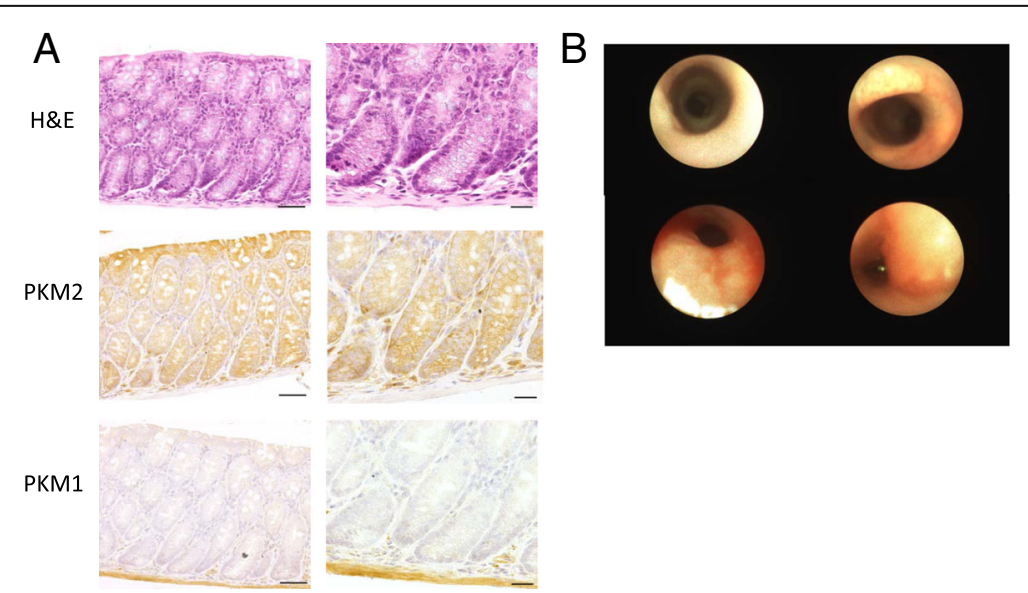

Fig. 1 PKM2 is expressed in colon epithelial cells where loss of APC results in tumor formation. a FFPE colon tissue sections from mice were stained with hematoxylin and eosin (H\&E) and isoform-specific antibodies against PKM2 or PKM1 as shown. Scale bars represent $50 \mu \mathrm{m}$ for all images at $\times 20$ magnification (left) and $20 \mu \mathrm{m}$ for all images at $\times 40$ magnification (right). b Adenoviral Cre was used to induce colon tumors, with ligation-restricting adenoviral Cre exposure to the distal colon. Lesion appearance and tumor progression were monitored by serial colonoscopy as shown. Representative tumors from four different $A p c^{\text {flox/flox }} P \mathrm{~km} 2^{\text {flox/flox }}$ mice are shown at various stages of progression 
A
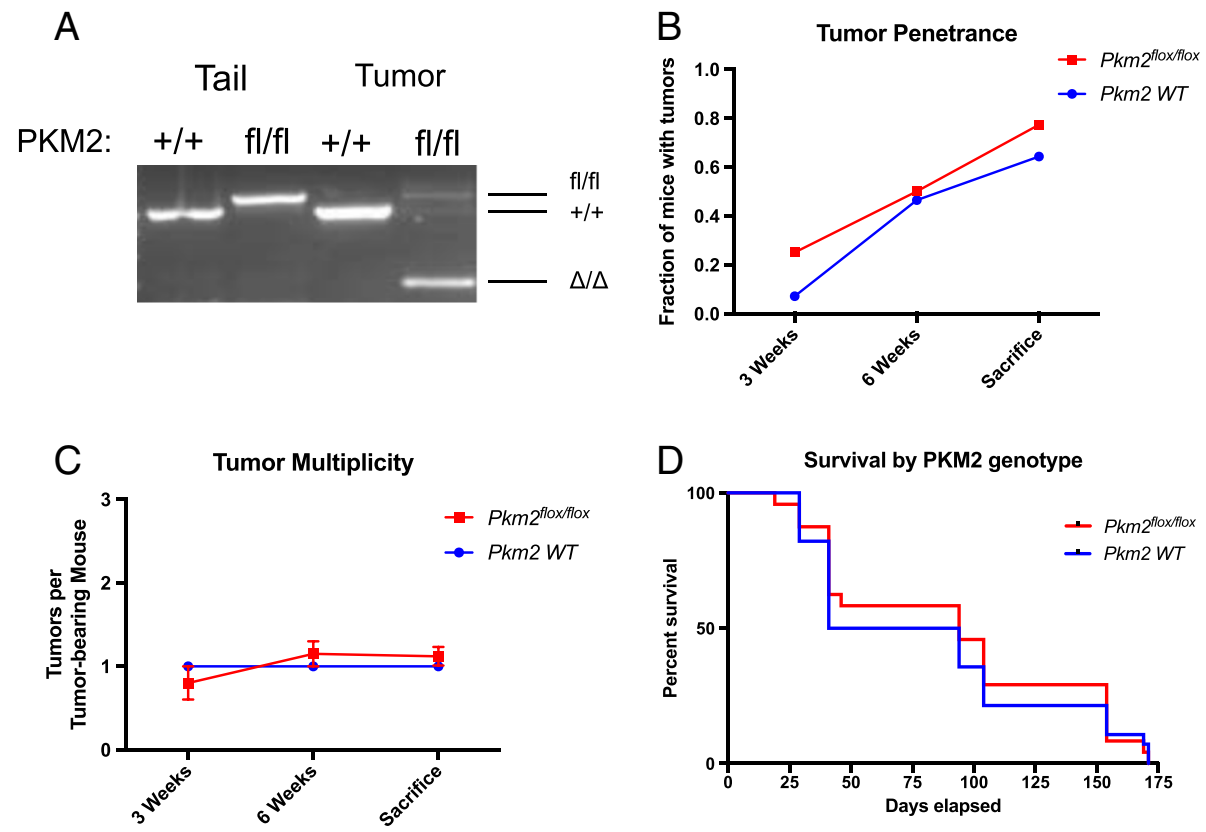

Fig. 2 PKM2 deletion does not affect tumor penetrance, multiplicity, or survival in mice with APC deletion. a Colon tumors were initiated in Apc flox/flox $P \mathrm{~km}^{+/+}$and $A p c^{\text {flox/flox }} P \mathrm{~km} 2^{\text {flox/flox }}$ mice, and PCR genotyping of the Pkm2 allele in tumors arising in each condition is shown. Analysis of tail DNA from $P \mathrm{~km}^{+/+}$and $P \mathrm{~km} 2^{\text {floxfflox }}$ mice is shown as a control. b Tumor penetrance in $A p c^{\text {floxflox }} P \mathrm{~km} 2^{+/+}$and $A p c^{\text {flox/flox }} P \mathrm{~km} 2^{\text {flox/flox }}$ mice was determined by colonoscopy. The fraction of mice with tumors did not differ significantly between cohorts at 3 weeks post-infection, at 6 weeks post-infection, or at final inspection ( $n=24 \mathrm{Pkm} 2^{\text {flox/flox }}$ mice, $28 \mathrm{Pkm}^{+/+}$mice per cohort, $p>0.1$ at all time points, Fisher's exact test). $\mathbf{c} A p c^{\text {flox/flox }} \mathrm{Pkm} 2^{\text {flox/flox }}$ mice had similar tumor multiplicity when compared to $A p c^{\text {flox/flox }} P \mathrm{~km}^{+/+}$mice. Multiplicity is defined as the number of tumors per tumor-bearing animal $\left(n=17 \mathrm{Pkm} 2^{\text {flox/flox }}\right.$ mice, $18 \mathrm{Pkm} 2^{+/+}$mice, $p>0.25$ ). d Kaplan-Meier curve showing survival of the $A p c^{\text {flox/flox }} P \mathrm{~km} 2^{+/+}$and $A p c^{\text {floxfllox }} P \mathrm{~km} 2^{\text {flox/flox }}$ cohorts. Pkm2 deletion had no statistically significant effect on survival $\left(n=24 \mathrm{Pkm} 2^{\text {floxflox }}\right.$ mice, $28 \mathrm{Pkm} 2^{+/+}$mice per cohort, $p=0.7060$, Log-rank (Mantel-Cox) test)

propria were confirmed in these same tissue sections (Additional file 1: Figure S1B). Colon tumors from $A p c^{\text {flox/flox}} ;$ P km $2^{\text {flox/flox }}$ mice showed loss of PKM2 expression in areas of the tumors; however, PKM2 expression was maintained in some areas and in normal colon tissue (Fig. 3b). Examination of serially stained sections showed that tumor areas with loss of PKM2 displayed expression of PKM1 (Fig. 3b), findings similar to what was previously observed in both tumor and normal tissue $[10,12,13]$.

The APC tumor suppressor protein is a negative regulator of canonical Wnt signaling. APC loss results in nuclear translocation of $\beta$-catenin, and strong nuclear $\beta$-catenin staining is observed in this colon cancer model [18]. Because work in glioblastoma has suggested that PKM2 is required for $\beta$-catenin activation downstream of EGF stimulation in that tissue [8], we determined whether loss of PKM2 impacted $\beta$-catenin localization in

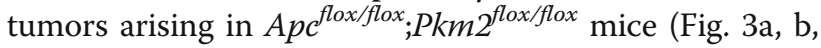
Additional file 1: Figure S1C). $\beta$-catenin staining was found only at the plasma membrane of non-transformed colon epithelial cells (Additional file 1: Figure S1C). In contrast, both PKM2 wild-type and PKM2-null tumor cells showed strong nuclear $\beta$-catenin staining (Fig. 3a, b,
Additional file 1: Figure S1C). These data suggest that PKM2 is not required for nuclear translocation of $\beta$ catenin downstream of APC loss in colon cancer.

To examine PKM2 expression in human colon tumors, we performed PKM2 immunohistochemistry on 41 colon tumor tissue array samples. Nearly half of the samples (20/41) were negative for PKM2 expression, and 18/41 expressed low levels of PKM2 (Fig. 4a, b). The lack of expression of PKM2 in human colon tumors further supports a model in which PKM2 upregulation is not required and is instead dispensable for the formation and growth of at least some colon tumors.

\section{Discussion}

Taken together, these results argue that PKM2 is not required for APC-deficient colon cancer. These findings are consistent with previous results suggesting that PKM2 is not required for BRCA1-deficient breast cancer [10], medulloblastoma [11], BCR-ABL-driven leukemia [12], or hepatocellular carcinomas with diverse genetics that arise in animals with metabolic syndrome [13]. While loss of PKM2 slowed leukemia progression, deletion of PKM2 increased breast cancer and medulloblastoma progression and could promote 


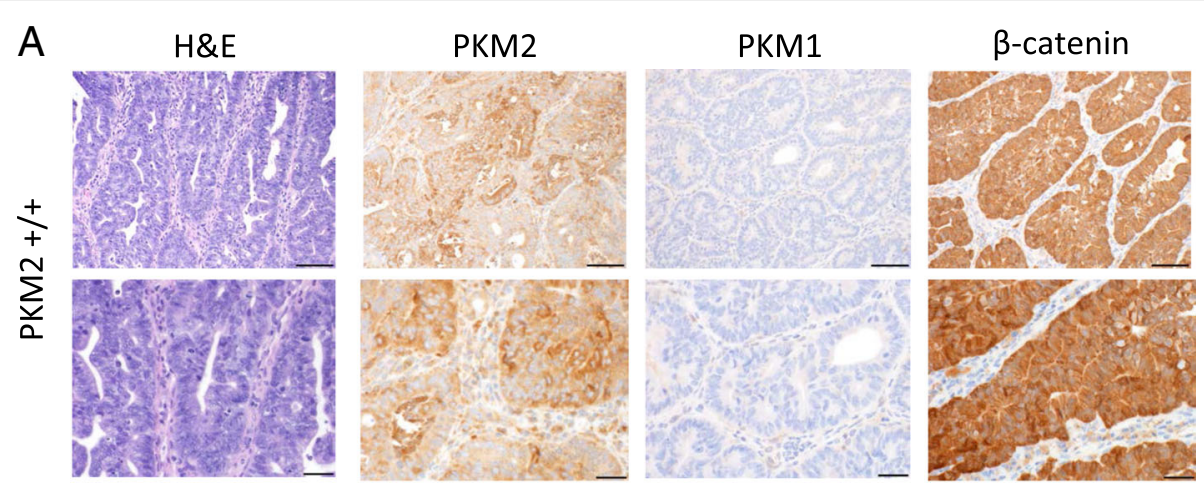

B

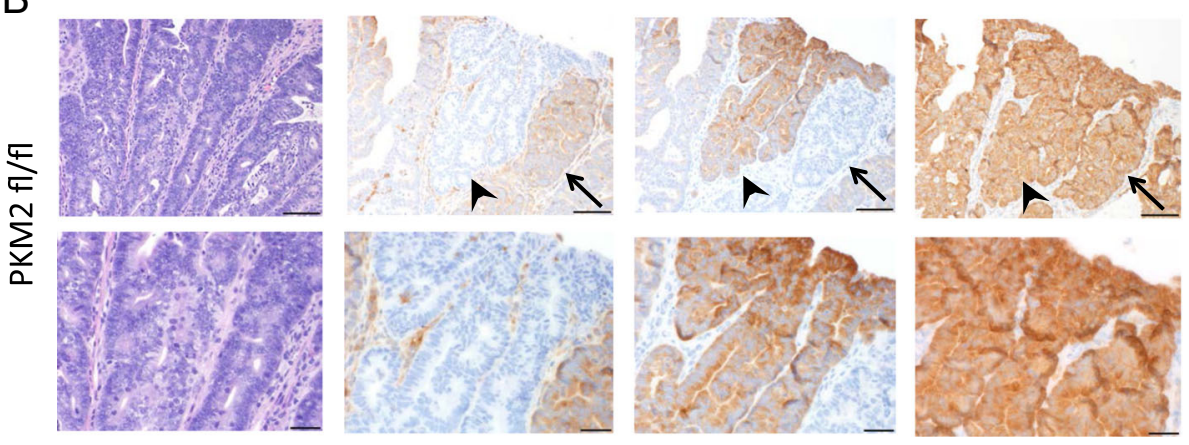

Fig. 3 PKM2 expression is lost in colon tumor cells in Pkm2 conditional animals. a Tissue sections from tumors arising in Apc floxflox $P$ km2 $2^{+/+}$mice were stained with hematoxylin and eosin (H\&E) or with antibodies against PKM2, PKM1, or $\beta$-catenin as shown. $\mathbf{b}$ Colon tumors arising in $A p c^{\text {flox/flox }} P$ km $2^{\text {flloxfllox }}$ mice were stained with hematoxylin and eosin (H\&E) or with antibodies against PKM2, PKM1, or $\beta$-catenin as shown. A PKM2 negative region that switches to PKM1 expression is marked with an arrowhead, and a PKM2 positive region is marked with an arrow. Scale bars represent $50 \mu \mathrm{m}$ for all images at $\times 20$ magnification (top row in each panel) and $20 \mu \mathrm{m}$ for all images at $\times 40$ magnification (bottom row in each panel)

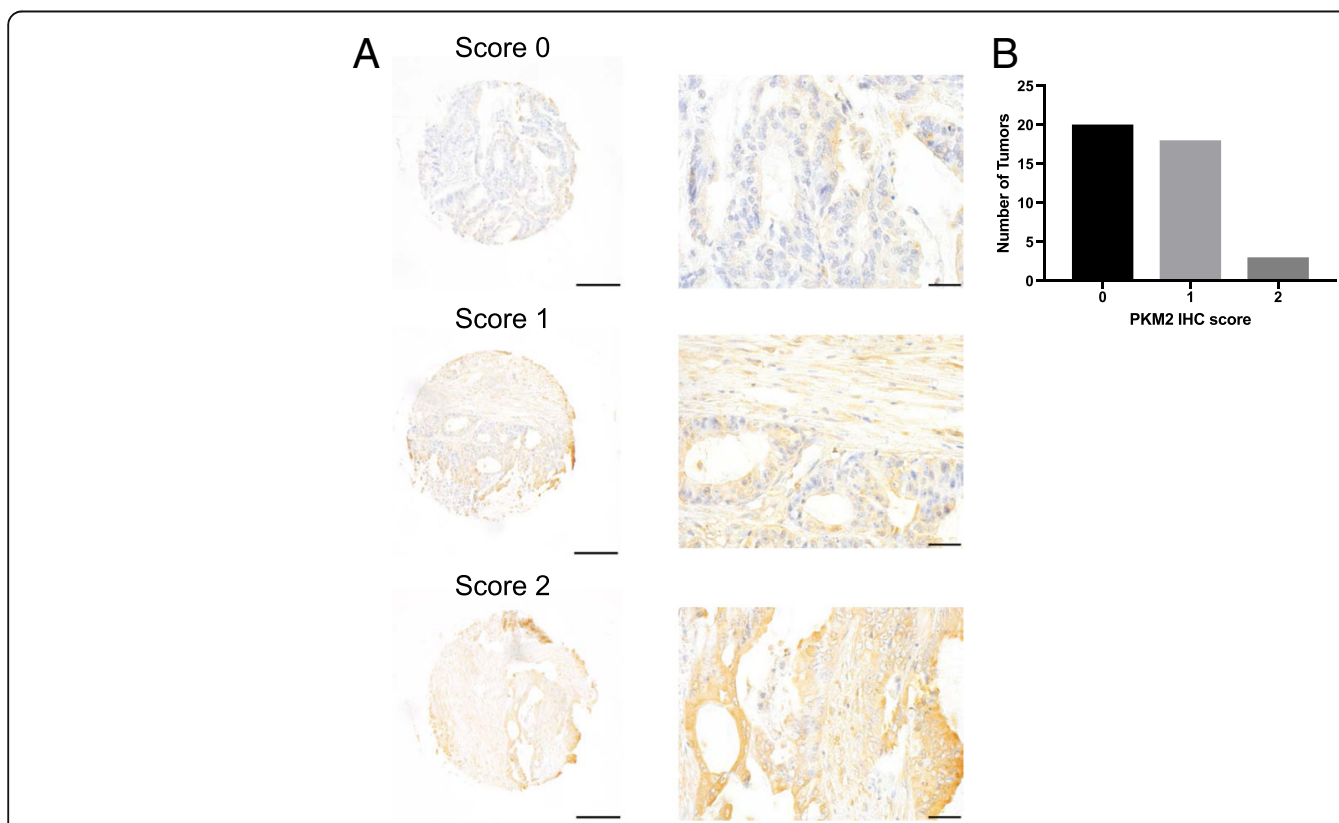

Fig. 4 Human colon tumors express low levels of PKM2. a Representative TMA cores containing human colon tumors showing PKM2 staining scored as 0,1 , or 2 . Scale bars represent $50 \mu \mathrm{m}$ for all images at $\times 20$ magnification (left) and $20 \mu \mathrm{m}$ for all images at $\times 40$ magnification (right). b Distribution of PKM2 staining intensities for 41 human colon tumors 
hepatocellular carcinoma. We find here that the absence of PKM2 does not prevent sporadic colon tumor initiation and progression, nor does it affect tumor multiplicity or survival. PKM2 expression was low and variable in PKM2 wild-type tumors, as well as in human colon tumors. An isoform switch from PKM2 to PKM1 expression was observed in PKM2null tumor regions, findings that are reminiscent of those observed in BRCA1 loss-driven breast cancer [10] or leukemia [12] models, and argue that dispensability of PKM2 is not limited to specific tumor types or to individual driver mutations. Recent work has shown that PKM2 is also dispensable during normal embryonic development, further supporting the idea that PKM2 is not necessary for cell proliferation in various physiological contexts [13].

Since PKM1 is constitutively active, whereas PKM2 activity can change between low activity and highactivity states, PKM1 expression has been associated with higher pyruvate kinase activity and decreased proliferation [10, 24]. Although we did not measure overall pyruvate kinase activity in PKM2 wild-type versus PKM2-null tumors, we did observe higher PKM1 expression in PKM2-null tumors. In contrast to other models where PKM2 has been deleted [24, 25], PKM1 expression following PKM2 deletion in the colon did not appear to affect tumor progression or proliferation. This may be related to the possibility that not all tumor cells efficiently deleted PKM2, as PKM2 expression was retained in some areas of the tumor, likely due to the multi-clonal nature of colon tumors in this model. The pattern of retained PKM2 expression is most consistent with inefficient deletion of PKM2 in some founder clones, as mixed cell populations of PKM2-expressing and deleted cells were not observed. This argues against a selective pressure to lose PKM2 expression in promoting tumor growth following APC loss. Nevertheless, the loss of PKM2 expression in some tumor areas suggests that PKM2 is not required for tumor formation in this model.

Our results demonstrate that nuclear localization of $\beta$-catenin downstream of canonical Wnt signaling is not dependent on PKM2. PKM2 has been reported to play a role in nuclear $\beta$-catenin localization through a Wntindependent mechanism downstream of EGF receptor signaling in glioblastoma [8]. Therefore, it is possible that PKM2 could play a role in $\beta$-catenin nuclear localization driven by EGF signaling in colon cancers where this pathway is hyperactive. Altered EGF receptor signaling can be a driver of colon cancer [26], and whether PKM2 has a different requirement in this context is not known. Nevertheless, these data argue against the requirement for a unique PKM2 activity in malignancy outside of specific contexts $[6,7,27,28]$. Instead, the findings support a model where PKM2 does not have a unique role but instead allows cancer cells to integrate metabolic and signaling inputs to support tumor growth.

\section{Conclusions}

Our study found that PKM2 is not required for colon tumor initiation or growth driven by APC loss. Loss of PKM2 in APC-deficient tumors resulted in higher PKM1 expression but did not change $\beta$-catenin expression patterns, further arguing that PKM2 is not required for $\beta$-catenin nuclear localization downstream of APC loss. Many human colon tumors examined in this study also were found to have very low or undetectable PKM2 expression, also supporting the conclusion that PKM2 is dispensable for the growth of some colon tumors.

\section{Methods}

\section{Mouse models and tumor induction}

$P k m 2^{\text {flox/flox }}$ mice [10] were bred to the $A p c^{C K O}$ mice [18] to generate animals of relevant genotypes. Ad5CMVcre adenovirus was obtained from the Gene Transfer Vector Core, University of Iowa. Surgeries to deliver Ad5CMVcre adenovirus to the colon were performed as described previously [18].

\section{Colonoscopy}

Mice were fasted overnight and anesthetized using 2\% isoflurane. The colon was washed with PBS and colonoscopy was performed using a custom-made system as described previously [18].

\section{Immunohistochemistry}

Sections from formalin-fixed paraffin-embedded tissue were stained with hematoxylin and eosin or with antibodies against PKM2 (Cell Signaling Technologies \#4053, 1:800 dilution), PKM1 (Cell Signaling Technologies \#7067, 1:1000 dilution), or $\beta$-catenin (BD Transduction Laboratories \#610153, 1:100 dilution) as previously described $[10,18]$. We analyzed a multi-tissue tissue microarray (TMA) containing tissue obtained from the archives of the Institute of Pathology at the University of Basel $[29,30]$. The TMA was scored for IHC intensity independently by both a pathologist (D.D.V.) and another member of the team (T.L.D.). Tumors that showed no positive staining for PKM2 were given a score of 0 , those with weak staining were given a score of 1 , and tumors with strong PKM2 staining were given a score of 2 .

\section{Additional file}

Additional file 1: Figure S1. Additional immunohistochemistry images. A) PKM2 wild-type tumors show variability in PKM2 staining; representative images of PKM2 staining in tumors from $A p c^{\text {flox/flox }} \mathrm{Pkm}^{+/+}$mice. B) PKM2 staining of normal colon and PKM1 staining of muscle fiber from the same 
sections of $A p c^{\text {floxfllox }} \mathrm{Pkm}^{+/+}$mice shown in Fig. 3a. C) $\beta$-catenin staining in normal areas (left panel, right panel marked with an arrowhead) and tumor tissue (right panel, marked with an arrow) of $\mathrm{Apc}^{\text {floxflox }} \mathrm{Pkm}^{+/+}$mice. Scale bars represent $50 \mu \mathrm{m}$ for all images at $\times 20$ magnification (left for each panel) and $20 \mathrm{um}$ for all images at $\times 40$ magnification (right for each panel). (DOCX $1650 \mathrm{~kb}$ )

\section{Abbreviations}

PKM1: Pyruvate kinase, M1 isoform; PKM2: Pyruvate kinase, M2 isoform

\section{Acknowledgements}

The authors thank the Swanson Biotechnology Center at the Koch Institute for assistance with histology and immunohistochemistry.

\section{Availability of data and materials}

All data generated or analyzed during this study are included in this published article.

\section{Authors' contributions}

ANL, WJI, JR, MJS, LG, TLD, ALH, OHY, and DDV performed and/or supervised the experiments. $\mathrm{KEH}$ and MGVH conceived and designed the study, and ANL and WJI provided input on study design. ANL, WJI, and MGVH wrote the manuscript with input from all authors who read and approved the final manuscript.

\section{Funding}

ANL is a Robert Black Fellow of the Damon Runyon Cancer Research Foundation, DRG-2241-15. WJ acknowledges support from the Sara and Frank McKnight Fund for Biochemical Research and NIH DP5OD021365. This research was supported in part by the Smith Family Foundation, the Burroughs Wellcome Fund, the Damon Runyon Cancer Research Foundation, SU2C, the Ludwig Center at MIT, and the National Cancer Institute including NIH 5P30CA1405141, R01CA211184, and R01CA168653. MGVH acknowledges additional support as a Howard Hughes Medical Institute Faculty Scholar.

\section{Ethics approval and consent to participate}

All mouse procedures were approved by the animal care and use committees at Tufts University Medical Center and/or MIT.

\section{Consent for publication}

Not applicable.

\section{Competing interests}

MGVH is a consultant and scientific advisory board member for Agios Pharmaceuticals and Aeglea Biotherapeutics. KEH is currently employed by Pfizer. The other authors declare they have no competing interests.

\section{Publisher's Note}

Springer Nature remains neutral with regard to jurisdictional claims in published maps and institutional affiliations.

\section{Author details}

${ }^{1}$ Koch Institute for Integrative Cancer Research and the Department of Biology at Massachusetts Institute of Technology, Cambridge, MA 02139, USA. ${ }^{2}$ Department of Biochemistry, University of Texas Southwestern Medical Center, Dallas, TX 75390, USA. ${ }^{3}$ Department of Medicine, Tufts Medical Center, Boston, MA 02111, USA. ${ }^{4}$ Center for Systems Biology, Massachusetts General Hospital, Boston, MA 02114, USA. ${ }^{5}$ Harvard Medical School, Boston, MA 02114, USA. ${ }^{6}$ Department of Pathology, Massachusetts General Hospital, Boston, MA 02114, USA. ${ }^{7}$ Departments of Surgery, Biomedical Sciences, and Pathology and Laboratory Medicine, Cedars-Sinai Medical Center, Los Angeles, CA, USA. ${ }^{8}$ Department of Medical Oncology, Dana-Farber Cancer Institute, Boston, MA 02115, USA.

Received: 11 May 2017 Accepted: 6 October 2017 Published online: 30 November 2017

\section{References}

1. Gui DY, Lewis CA, Vander Heiden MG. Allosteric regulation of PKM2 allows cellular adaptation to different physiological states. Sci Signal. 2013;6:pe7.
2. Chaneton B, Gottlieb E. Rocking cell metabolism: revised functions of the key glycolytic regulator PKM2 in cancer. Trends Biochem Sci. 2012;37:309-16

3. McKnight SL. Please keep me 2uned to PKM2. Mol Cell. 2014:53:683-4.

4. Hosios AM, Fiske BP, Gui DY, Vander Heiden MG. Lack of evidence for PKM2 protein kinase activity. Mol Cell. 2015;59:850-7.

5. Jiang Y, Li X, Yang W, Hawke DH, Zheng Y, Xia Y, et al. PKM2 regulates chromosome segregation and mitosis progression of tumor cells. Mol Cell. 2014;53:75-87.

6. Yang W, Xia Y, Hawke D, Li X, Liang J, Xing D, et al. PKM2 phosphorylates histone $\mathrm{H} 3$ and promotes gene transcription and tumorigenesis. Cell. 2012; 150:685-96.

7. Gao X, Wang H, Yang JJ, Liu X, Liu ZR. Pyruvate kinase M2 regulates gene transcription by acting as a protein kinase. Mol Cell. 2012;45:598-609.

8. $\quad$ Yang $W$, Xia Y, Ji H, Zheng Y, Liang J, Huang W, et al. Nuclear PKM2 regulates beta-catenin transactivation upon EGFR activation. Nature. 2011; 480:118-22.

9. Cortes-Cros M, Hemmerlin C, Ferretti S, Zhang J, Gounarides JS, Yin H, et al. M2 isoform of pyruvate kinase is dispensable for tumor maintenance and growth. Proc Natl Acad Sci U S A. 2013;110:489-94.

10. Israelsen WJ, Dayton TL, Davidson SM, Fiske BP, Hosios AM, Bellinger G, et al. PKM2 isoform-specific deletion reveals a differential requirement for pyruvate kinase in tumor cells. Cell. 2013;155:397-409.

11. Tech K, Tikunov AP, Farooq H, Morrissy AS, Meidinger J, Fish T, et al. Pyruvate kinase inhibits proliferation during postnatal cerebellar neurogenesis and suppresses medulloblastoma formation. Cancer Res. 2017; 77:3217-3230.

12. Wang YH, Israelsen WJ, Lee D, Yu WW, Jeanson NT, Clish CB, et al. Cell-statespecific metabolic dependency in hematopoiesis and leukemogenesis. Cell. 2014;158:1309-23.

13. Dayton TD, Gocheva V, Miller KM, Israelsen WJ, Bhutkar A, Clish CB, et al Germline loss of PKM2 promotes metabolic distress and hepatocellular carcinoma. Genes Dev. 2016;30:1020-33.

14. Christofk HR, Vander Heiden MG, Harris MH, Ramanathan A, Gerszten RE, Wei $R$, et al. The M2 splice isoform of pyruvate kinase is important for cancer metabolism and tumour growth. Nature. 2008:452:230-3.

15. Zhou CF, Li XB, Sun H, Zhang B, Han YS, Jiang Y, et al. Pyruvate kinase type $\mathrm{M} 2$ is upregulated in colorectal cancer and promotes proliferation and migration of colon cancer cells. IUBMB Life. 2012;64:775-82.

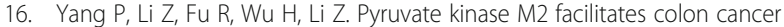
cell migration via the modulation of STAT3 signalling. Cell Signal. 2014;26: 1853-62.

17. Hamabe A, Konno M, Tanuma N, Shima H, Tsunekuni K, Kawamoto K, et al. Role of pyruvate kinase $\mathrm{M} 2$ in transcriptional regulation leading to epithelial-mesenchymal transition. Proc Natl Acad Sci U S A. 2014;111:15526-31.

18. Hung KE, Maricevich MA, Richard LG, Chen WY, Richardson MP, Kunin A, et al. Development of a mouse model for sporadic and metastatic colon tumors and its use in assessing drug treatment. Proc Natl Acad Sci U S A. 2010;107:1565-70

19. Roper J, Richardson MP, Wang WV, Richard LG, Chen W, Coffee EM, et al. The dual PI3K/mTOP inhibitor NVP-BEZ235 induces tumor regression in a genetically engineered mouse model of PIK3CA wild-type colorectal cancer. PLoS One. 2011;6:e25132.

20. Roper J, Sinnamon MJ, Coffee EM, Belmont P, Keung L, Georgeon-Richard L, et al. Combination PI3K/MEK inhibition promotes tumor apoptosis and regression in PI3KCA wild-type, KRAS mutant colorectal cancer. Cancer Lett. 2014;347:204-11.

21. Coffee EM, Faber AC, Roper J, Sinnamon MJ, Goel G, Keung L, et al. Concomitant BRAF and PI3K/mTOR blockade is required for effective treatment of BRAF(V600E) colorectal cancer. Clin Cancer Res. 2013;19: 2688-98.

22. Martin ES, Belmont PJ, Sinnamon MJ, Richard LG, Yuan J, Coffee EM, et al. Development of a colon cancer GEMM-derived orthotopic transplant model for drug discovery and validation. Cancer Res. 2013;19:2929-40.

23. Imamura K, Tanaka T. Multimolecular forms of pyruvate kinase from rat and other mammalian tissues. I. Electrophoretic studies. J Biochem. 1972:71:1043-51.

24. Anastasiou D, Yu Y, Israelsen WJ, Jiang JK, Boxer MB, Hong BS, et al. Pyruvate kinase $\mathrm{M} 2$ activators promote tetramer formation and suppress tumorigenesis. Nat Chem Biol. 2012:8:839-47. 
25. Lunt SY, Muralidhar V, Hosios AM, Israelsen WJ, Gui DY, Newhouse L, et al. Pyruvate kinase isoform expression alters nucleotide synthesis to impact cell proliferation. Mol Cell. 2015;57:95-107.

26. Moroni M, Veronese S, Benvenuti S, Marrapese G, Sartore-Bianchi A, Di Nicolantonio F, et al. Gene copy number for epidermal growth factor receptor (EGFR) and clinical response to antiEGFR treatment in colorectal cancer: a cohort study. Lancet Oncol. 2005;6:279-86.

27. Keller KE, Doctor ZM, Dwyer ZW, Lee YS. SAICAR induces protein kinase activity of PKM2 that is necessary for sustained proliferative signaling of cancer cells. Mol Cell. 2014;53:700-9.

28. Lv L, Xu YP, Zhao D, Li FL, Wang W, Sasaki N, et al. Mitogenic and oncogenic stimulation of K433 acetylation promotes PKM2 protein kinase activity and nuclear localization. Mol Cell. 2013;52:340-52.

29. Schraml P, Kononen J, Bubendorf F, Moch H, Bissig H, Nocito A, et al. Tissue microarrays for gene amplification surveys in many different tumor types. Clin Cancer Res. 1999;5:1966-75.

30. Baumhoer D, Tornillo L, Stadlmann S, Roncalli M, Diamantis EK, Terracciano LM. Glypican 3 expression in human nonneoplastic, preneoplastic, and neoplastic tissues: a tissue microarray analysis of 4,387 tissue samples. Am J Clin Pathol. 2008;129:899-906

\section{Submit your next manuscript to BioMed Central} and we will help you at every step:

- We accept pre-submission inquiries

- Our selector tool helps you to find the most relevant journal

- We provide round the clock customer support

- Convenient online submission

- Thorough peer review

- Inclusion in PubMed and all major indexing services

- Maximum visibility for your research

Submit your manuscript at www.biomedcentral.com/submit 